\title{
Visual Abilities Distinguish Level of Play in Rugby
}

\author{
${ }^{1}$ Lourens Millard ${ }^{*},{ }^{1}$ Brandon Shaw, ${ }^{1}$ Gerrit Breukelman, ${ }^{1}$ Ina Shaw \\ ${ }^{1}$ Department of Human Movement Science, University of Zululand, Richards Bay, South Africa.
}

Submitted 13 July 2020; Accepted in final form 15 September 2020.

\begin{abstract}
Background. Novices in sport possesses similar visual skills to that of experts, however there may be major differences in magnitude of performance in these skills, with expert athletes only demonstrating superiority in specific vision skills and not all aspects of vision. Objectives. In this vain, the aim of this study was to discern whether Premier League rugby players has enhanced visio-spatial skills in comparison to First Division rugby players. Methods. Thus, the present study compared the performance of Premier League rugby players $(n=40)$ and First Division rugby players $(n=40)$ on six specific components of vision, namely; accommodation facility, saccadic eye movement, speed of recognition, peripheral awareness, visual memory, and hand-eye coordination. Results. Premier League rugby players performed significantly $(\mathrm{p}=0.001)$ better than the First Division rugby players in five of the six tests. but were found to be similar in visual memory performance $(\mathrm{p}=0.810)$. Conclusion. While this study substantiates the proposal that expert athletes, and specifically rugby players, have superior visual expertise to novice athletes, this study also found that this is not the case with all vision skills. The present study's findings suggest that sport-specific vision testing batteries may be required to distinguish high performers from low performers in the same vein as physical tests are utilised in the selection and recruitment of athletes.
\end{abstract}

\section{KEYWORDS: Sport, Visio-Spatial Intelligence, Vision, Visual Performance, Visual Testing.}

\section{INTRODUCTION}

Rugby union is one of the most popular professional team sports in the world, and has become increasingly professionalized in modern times $(1,2)$. This professionalism has resulted in a need for rugby players, whether full-time or amateur, to achieve an ever-increasing level of conditioning (1). To meet these ever-increasing demands, rugby players spend thousands of hours improving inter alia their body composition, cardiorespiratory fitness, muscular fitness, and flexibility amongst others (2).

However, increasing professionalism combined with increasing technologies has made sport much more complex (3). It is this ability to better interrogate an athlete that has led to the increasing importance of sports vision testing in athletes. This is especially true in rugby in that to perform optimally in a ball sport such as rugby, experts suggest that player's in these sports require a "great eye", superb vision or excellent peripheral vision (4). Visual skills are particularly important in rugby as players need to perform skills catching, passing and kicking to allow for the ball to be advanced up the field beyond the opposing team's defensive line (5).

While research pertaining to vision expertise in rugby players has indicated that rugby players have enhanced skills when compared to non-athletes (6, 7), no research exists to determine if rugby players at different levels of play exhibit different levels of visual expertise, which necessitates a study in this vain. At present, it has been suggested that novices in sport may possesses similar visual skills to that of experts playing at a higher level (8). However,

*. Corresponding Author:

Lourens Millard, MA

E-mail: millardL@unizulu.ac.za 
there is evidence to suggest that experts only excel in relation to certain visual skills, such as the cognitive aspects of vision, which include visual perception, visual concentration, visual reaction time, central peripheral awareness, and visualization (8). Research further suggests that visual skills such as visual acuity, accommodation and fusion remain relatively consistent for both novice and expert rugby players (8). A further explanation as to why some research demonstrates that there is no difference between experts and novices is due to the generalized tests utilized that only measure the visual reception of information rather than the sport-specific, perceptual interpretation of information (9). While novices in sport possesses similar visual skills to that of experts playing at a higher level, there may be major differences in magnitude of performance in these skills. This may necessitate the determination of which vision tests are able to discriminate high performers from low performers in the same vein as physical tests would. This would allow for the eventual development of sport-specific vision testing batteries.

\section{MATERIALS AND METHODS}

Participants. The study sampled 19- to 35-year old male First Division rugby players $(n=40$; mean age: $23.88 \pm 4.36$ years) and male Premier League rugby club players $(n=40$; mean age: $25.20 \pm 5.23$ years). Rugby players from both groups were sampled from Kwazulu-Natal province using a nonprobability sampling technique. Inclusion criteria were (a) players with normal (20/20) vision, (b) participation in a minimum of 30 hours of rugby training and (c) played at least one competitive game per week in the Premier League and/or First Division. Exclusion criteria were (a) players with visual impairments that caused a loss of vision, (b) players that did not participate in a minimum of 30 hours of training and one competitive game per week, (c) players that were injured or had recent surgery (eye surgery or otherwise). All participants provided informed written consent, and our study protocol was approved by the Institutional Review Boards of the University of Zululand. The study protocol conforms to the ethical guidelines of the 1975 Declaration of Helsinki.

Procedures. All participants undertook a general optometric assessment using the Spectrum Eyecare software (Version 6.0.0, Digital Optometry, Republic of South Africa) to conclude whether any limitations existed in any of the participants' vision and thus suitability for the study (5). All participants included in the study presented with normal vision.

Testing was performed on weekday mornings between 07:00 and 12:00 in the post-absorptive state following a 9- to 12-hour fast to minimize the influence of any dietary or supplemental factors (5). In an attempt to avoid any physical and mental influences, participants were tested only after at least 48 hours following any physical exercise. Both groups performed the same visio-spatial skills (VSS) test battery and tests were performed in the following sequence to ensure prior tests did not influence later tests: 1) accommodation facility; 2) saccadic eye movements; 3) speed of recognition; 4) hand/eye coordination; 5) peripheral awareness and 6) visual memory. A five-minute rest period was observed between each trial to ensure adequate recovery (5).

The Hart Near Far Rock Test was utilized to assess visual accommodation (5). The Hart Near Far Rock chart was placed at head height and $3 \mathrm{~m}$ away from each participant. Another smaller chart was held at arm's length away from each participant. At the instruction of the primary researcher, the first letter of the first line of the chart on the wall 3 meters (m) away was read, after which the first letter on the closer chart was read (5). The test lasted 30 seconds (sec) and the final score calculated by subtracting errors from the end score. The best score of two trials was utilized in the data analysis (5).

A standardized saccadic eye movement chart with adjustable letters was utilized to ensure letters could not be memorized (5). Two such charts were spaced $1 \mathrm{~m}$ apart were placed on a wall $3 \mathrm{~m}$ away from each participant. At the instruction of the primary researcher, participants were required to read aloud the first letter on the lateral side of the left chart and then immediately move over to the chart on the right and to read aloud the corresponding first letter on the lateral side. This test lasted $30 \mathrm{sec}$ and the final score calculated by number of correct matched letters read aloud (5).

To measure speed of recognition, the present study made use of the Batak Pro (5). The Batak Pro's Evasion Program, which was controlled by a microcomputer, randomly illuminated any of the 12 visually bright light emitting diode (LED) targets for $1 \mathrm{sec}$ for a maximum of 100 times (5). Each target remained illuminated for $1 \mathrm{sec}$. However, if the participant pressed the wrong target or failed to touch the target, the entire routine sped up. Further, participants were not 
required to touch flashing targets and if such a target was touched, the microcomputer subtracted five points for each incorrect flashing target touched. In the Evasion Program, the center targets infrequently illuminated at the same time, requiring participants to immediately avoid an infrared beam emitted or be penalized five points. The Batak Pro automatically recorded the end score and the better of two trials were utilized in the data analysis (5).

In order for hand-eye coordination to be assessed, the current study used the ball wall toss using a standard tennis ball (5). Each participant was required to throw the ball at a mark on a wall $2 \mathrm{~m}$ away. When the ball returned, each participant attempted to catch the ball using alternating hands for a duration of $30 \mathrm{sec}$. The highest number of successful catches attained from one of the two trials was used in the data analysis (5).

The Batak Pro (5) was utilized to assess peripheral awareness using the Accumulator Program. This program caused random targets to light up, and remain lit on the Batak Pro for $60 \mathrm{sec}$ until the participant touched them (5). A microprocessor recorded the number of targets correctly touched in the $60 \mathrm{sec}$ with the best score of the two trials utilized in the data analysis.

The Batak Pro (5) Flash Program was utilized to assess visual memory. The Flash Program illuminated six random targets for a display time of $1 / 2 \mathrm{sec}$ and participants were required to remember not only the specific light lit, but also the order in which they were activated (5). The maximum score was recorded, and best score attained during two trials was utilized in the data analysis.

Data Analysis. This study utilized quantitative research methods, making use of already established visual skill assessments. Descriptive statistics including the means, standard deviations, ranges and percentage difference were calculated while the MannWhitney $U$ test was applied to compare the differences between the two independent groups employed post hoc rank-ordered analysis was conducted to more accurately and empirically evaluate which group had more superior visual skills. An exploratory factor analysis was also applied post hoc to create an overall combined measure of visual expertise. This was applied following the application of the Kaiser-MeyerOlkin Measure of Sampling Adequacy to indicate whether the data was suitable for factor analysis and following Bartlett's Test of Sphericity to determine if the data was suitable for reduction for exploratory factor analysis. The Statistical Package for Social Sciences (SPSS) version 22 for Windows (SPSS Inc., Chicago, IL, USA) was used for the purposes of this study and statistical confidence set at $\mathrm{p}<0.05$.

\section{RESULTS}

The results indicated that a significant difference $(\mathrm{p}=0.001)$ existed between the Premier League rugby players and First Division rugby players for five out of the six tests (Table 1). Specifically, it was found that the Premier League rugby players significantly bested the First Division rugby players with regards to accommodation facility $(\mathrm{p}=0.001)$, saccadic eye movement $(\mathrm{p}=0.001)$, speed of recognition $(\mathrm{p}=$ $0.001)$, hand/eye coordination $(\mathrm{p}=0.001)$ and peripheral awareness $(\mathrm{p}=0.001)$, but not visual memory $(\mathrm{p}=0.810)$.

Post hoc analysis using rank-ordered analysis indicated that the Premier League rugby players were $46 \%$ more proficient than First Division rugby players at speed of recognition, followed by accommodation facility at $19 \%$, hand-eye coordination and saccadic eye movement at $18 \%$, and lastly peripheral awareness at $15 \%$ (Table 1).

Following further exploratory analysis, a statistically significant difference existed for the overall performance between Premier League and First Division rugby players $(\mathrm{U}=173.000$, $\mathrm{p}$-value $=0.001$ ), with Premier League athletes performing better on average than First Division athletes.

Table 1. Visual abilities distinguished between premier league rugby players and first division ruby players

\begin{tabular}{lcccc}
\hline Visual skill & $\begin{array}{c}\text { First Division Rugby } \\
\text { players }(\mathbf{n = 4 0 )}\end{array}$ & $\begin{array}{c}\text { Premier Rugby players } \\
(\mathbf{n = 4 0 )}\end{array}$ & Difference (\%) & Significance (p-value) \\
\hline Accommodation & $31.68 \pm 4.29$ & $38.33 \pm 4.39$ & 18.99 & $0.001^{*}$ \\
Facility & & & & $0.001^{*}$ \\
Saccadic Eye Movement & $40.03 \pm 7.26$ & $47.70 \pm 6.61$ & 17.49 & $0.001^{*}$ \\
Speed of Recognition & $30.88 \pm 15.35$ & $49.53 \pm 14.31$ & 46.39 & $0.001^{*}$ \\
Peripheral Awareness & $65.40 \pm 6.13$ & $76.02 \pm 4.28$ & 15.02 & $0.001^{*}$ \\
Hand-Eye Coordination & $24.75 \pm 3.68$ & $29.70 \pm 3.50$ & 18.18 & 0.810 \\
\hline Visual Memory & $45.28 \pm 7.01$ & $45.70 \pm 5.96$ & 0.92 & \\
\hline
\end{tabular}

Mean \pm SD; *Statistically significant $(\mathrm{p}<0.05)$ 


\section{DISCUSSION}

The present study investigated and compared the performance of Premier League rugby players and First Division rugby players on six specific components of vision. Results indicated that Premier League rugby players performed better than the First Division rugby players in five of the six tests, but not in visual memory performance.

Based on the results of accommodation facility, previous research by Ghasemi et al. (2009), and Jafarzadehpur and Yarigholi (2004) has found similar differences in accommodation facility when comparing experts and novices, albeit in soccer referees and table tennis champions, respectively $(10,11)$. However, Roberts et al. (2017) found no difference in accommodation facility when comparing novice and expert soccer players (12). Interestingly, expert athletes, when compared to novices, may have an increased accommodation facility due to having a better developed visual system that allows a quicker and more efficient adjustment of their eyes from a far to a near target (12). This more efficient adjustment may allow experts to better track objects like a ball in rugby (12).

While Kishita et al. (2020), and Yilmaz and Polat (2018) found that there was no difference in saccadic eye movements when comparing expert and novice tennis players, volleyball players, basketball players, and swimmers, respectively $(13,14)$, the finding of superior saccadic eye movements in Premier League rugby players concurs with studies conducted by Jafarzadehpur et al. (2007), and Gegenfurtner et al. (2011) who found a significant difference in saccadic eye movements when comparing expert and novice volleyball players $(15,16)$. Experts may have superior saccadic eye movements to novices due to saccadic eye movements having different underlying neural visual mechanisms, as well as different neural motor mechanisms that allow for improvement through large amounts of training (6). However, previous research has also found that experts do not have shorter latencies for the initiation of pursuit or saccadic eye movements as it is a visual hardware skill and cannot be improved through training $(13,14)$. This supposition would imply that no difference exists in saccadic eye movements between experts and novices in any sports and is proved incorrect by the present study.
Speed of recognition of Premier League rugby players was found to be superior to First Division rugby players in this study. This is similar to the studies of Diaz del Campo et al. (2011) and Lorains et al. (2013) who found difference in speed of recognition when comparing expert and novice soccer and Australian football players (17, 18). However, Breed et al. (2018) found no difference in speed of recognition when comparing experts and novices in Australian football players (19). The lack of changes in that study may have been due to expert athletes in those sports not using sport-specific tests since expert athletes may only have superior recall when it comes to task-specific experiences (6). The lack of superiority in those studies does also not imply that speed of recognition is not important in those sports since the need for efficiency of decision-making with regard to response execution and inhibition is clear in those sports (20). Interestingly, this study found that speed of recognition may be the most critical visual skill of the six measured, due to the $46 \%$ difference and rank ordering, when assessing whether a rugby player can be viewed as an expert or a novice (5).

Peripheral awareness was found to be superior in the present study's Premier League rugby players and is supported by the previous findings of Schumacher et al. (2019) (21). However, Abernethy and Wood (2001), and Ryu et al. (2013) found no differences in peripheral awareness when comparing expert and novices in racquet sports and soccer players, respectively $(9$, 22). A possible reason as to why no significant differences was found in the studies of Abernethy and Wood (2001), and Ryu et al. (2013) may be that in order to find significant difference in peripheral awareness, the tests need to be more sport-specific and not have generalized measures $(9,22)$. In this regard, Abernethy and Wood (2001) stated that generalized (non-specific) tests only measure the visual reception of information rather than the sport-specific, perceptual interpretation of information (9). The latter is critical in distinguishing the visual-perceptual skill of expert and novice performers, which in turn, means that if a peripheral awareness test lacks specificity, it will lead to non-significant results.

The present study further demonstrated that a difference existed in hand-eye coordination 
between the Premier League and First Division rugby players. The findings of Paul et al. (2011), and Przednowek et al. (2019) concur with the current study and also found differences in handeye coordination between expert and novice table tennis players, and handball players, respectively $(23,24)$. Experts athletes generally have better skill, accuracy and spatio-temporal constraints on visual information acquisition, which leads to enhanced hand-eye coordination, and thus improved athletic performance (24).

The only visual skill of the six measured to be found to be similar in the present's expert and novice rugby players study was visual memory. While no studies could be found to support or disprove this finding, this finding may be due to the expert rugby players not exhibiting superior recall when presented with unstructured movements, suggesting that the superior recall of experts only occur when faced with task-specific experiences (25). Thus, this finding may suggest several possibilities including that visual memory is not important to rugby prowess, that visual memory cannot distinguish level of play in rugby players and that an upper-limit of visual memory exists in that sport or The Batak Pro Flash Program is not able to distinguish prowess in rugby players. However, these suppositions require more research.

\section{LIMITATIONS}

The test battery designed for this study is novel, and as such has never before been applied to rugby players, and no norms have been created to compare the results to. The six visio-spatial skills selected for this study were identified through reviewing other research, and there is still the possibility that other visio-spatial skills applicable to rugby still need to be addressed. In addition, the sample size of the study only allowed for a limited number of players to be tested. Future studies should investigate whether there are other VSS that needs to be identified and tested, specifically for rugby players in order to assist with improving high performance testing and training specifically in relation to vision.

\section{CONCLUSION}

While this study substantiates the proposal that expert rugby players have superior visual expertise to lower level rugby players, this study also found that this is not the case with all visual skills. Further, this study's findings suggest that sport-specific vision testing batteries may be required to distinguish high performers from low performers in the same vein as physical tests are utilised in the selection and recruitment of athletes and to measure the transferability of visual training to on-pitch performance.

\section{APPLICABLE REMARKS}

- This study assists in designing courses and workshops to create a better understanding for coaches and role players of rugby union as to the importance of visual skills testing in order to gain a competitive advantage.

- The test battery included in this study assists in identifying talent in a different way than the traditional physiological and anthropometrical methods used, as the ability of athletes to make decisions in pressure situations is what differentiates a great player from a good player.

\section{REFERENCES}

1. Horsley IG, Fowler EM, Rolf CG. Shoulder injuries in professional rugby: a retrospective analysis. $J$ Orthop Surg Res. 2013;8:9. http://dx.doi.org/10.1186/1749-799X-8-9 http://ncbi.nlm.nih.gov/pubmed/23618008

2. Lynch E, Jj Lombard A, Coopoo Y, Shaw I, B SS. Shoulder injury incidence and severity through identification of risk factors in rugby union players. Pak J Med Sci. 2013;29(6):1400-1405. http://dx.doi.org/10.12669/pjms.296.3769 http://ncbi.nlm.nih.gov/pubmed/24550962

3. Du Toit PJ, Krüger PE, Fowler KF, Govender C, Clark J. Influence of sports vision techniques on adult male rugby players. African $J$ Physic Health Edu Rec Dance. 2010;16(3). http://dx.doi.org/10.4314/ajpherd.v16i3.60931

4. Millard L, Shaw I, Breukelman GJ, Shaw BS. Factors Affecting Vision and Visio-Spatial Intelligence (VSI) in Sport: A Review of the Literature. Asian J Sport Med. 2020; In Press(In Press). http://dx.doi.org/10.5812/asjsm.101670

5. Millard L, Shaw I, Breukelman GJ, Shaw BS. Visio-spatial skills in athletes: comparison of rugby players and non-athletes. Sport Sci Health. 2020;3(2):1-7. http://dx.doi.org/10.1007/s11332-020-00663-1

6. Khanal S. Impact of Visual Skills Training on Sports Performance: Current and Future Perspectives. Adv Ophthalmol Visual Sys. 2015;2(1):26-28. http://dx.doi.org/10.15406/aovs.2015.02.00032 
7. Clark J, Betz B, Borders L, Kuehn-Himmler A, Hasselfeld K, Divine J. Vision Training and Reaction Training for Improving Performance and Reducing Injury Risk in Athletes. J Sport Perform Vision. 2020;2(1):e8-e16. http://dx.doi.org/10.22374/jspv.v2i1.4

8. Jansen van Vuuren P, Henning E, Kleynhans M, Terblanche HC, Crafford D, Grobbelaar C, et al. The effect of sport specific exercises on the visual skills of adult rugby players. Suid-Afrikaanse Tydskrif vir Natuurwetenskap en Tegnologie. 2014;33(1). http://dx.doi.org/10.4102/satnt.v33i1.1234

9. Abernethy B, Wood JM. Do generalized visual training programmes for sport really work? An $\begin{array}{lllll}\text { experimental investigation. } J & J & \text { Sports } & \text { Sci. }\end{array}$ http://dx.doi.org/10.1080/026404101750095376 http://ncbi.nlm.nih.gov/pubmed/11256825

10. Ghasemi A, Momeni M, Rezaee M, Gholami A. The Difference in Visual Skills Between Expert Versus Novice Soccer Referees. J Hum Kinetic. 2009;22(1):15-20. http://dx.doi.org/10.2478/v10078-009-0018-1

11.Jafarzadehpur E, Yarigholi MR. Comparison of visual acuity in reduced lumination and facility of ocular accommodation in table tennis champions and non- players. J Sports Sci Med. 2004;3(1):44-48. http://ncbi.nlm.nih.gov/pubmed/24497820

12. Roberts JW, Strudwick AJ, Bennett SJ. Visual function of English Premier League soccer players. Sci Med Football. 2017;1(2):178-182. http://dx.doi.org/10.1080/24733938.2017.1330552

13. Kishita Y, Ueda H, Kashino M. Eye and Head Movements of Elite Baseball Players in Real Batting. Frontiers Sport Act Living. 2020;2(3):1-12. http://dx.doi.org/10.3389/fspor.2020.00003

14. Yilmaz A, Polat M. Prosaccadic and antisaccadic performance of the athletes in different types of sports. Biomed Res. 2018;29(3):539-543. http://dx.doi.org/10.4066/biomedicalresearch.29-17-3224

15.Jafarzadehpur E, Aazami N, Bolouri B. Comparison of saccadic eye movements and facility of ocular accommodation in female volleyball players and non-players. Scand J Med Sci Sports. 2007;17(2):186190. http://dx.doi.org/10.1111/j.1600-0838.2005.00535.x http://ncbi.nlm.nih.gov/pubmed/17394481

16. Gegenfurtner A, Lehtinen E, Säljö R. Expertise Differences in the Comprehension of Visualizations: a Meta-Analysis of Eye-Tracking Research in Professional Domains. Edu Psycho Rev. 2011;23(4):523552. http://dx.doi.org/10.1007/s10648-011-9174-7

17. Diaz del Campo DG, Gonzalez Villora S, Garcia Lopez LM, Mitchell S. Differences in decision-making development between expert and novice invasion game players. Percept Mot Skills. 2011;112(3):871888.

http://ncbi.nlm.nih.gov/pubmed/21853776

http://dx.doi.org/10.2466/05.10.11.25.PMS.112.3.871-888

18. Lorains M, Ball K, MacMahon C. Expertise differences in a video decision-making task: Speed influences on performance. Psycho Sport Exercise. 2013;14(2):293-297. http://dx.doi.org/10.1016/j.psychsport.2012.11.004

19. Breed R, Mills O, Spittle M. Can video-based perceptual-cognitive tests differentiate between skill level, player position, and experience in elite australian football? J Expert. 2018;1(1):79-93.

20.Di Russo F, Taddei F, Apnile T, Spinelli D. Neural correlates of fast stimulus discrimination and response selection in top-level fencers. Neurosci Lett. 2006;408(2):113-118. http://dx.doi.org/10.1016/j.neulet.2006.08.085 http://ncbi.nlm.nih.gov/pubmed/17018246

21. Schumacher N, Schmidt M, Reer R, Braumann KM. Peripheral Vision Tests in Sports: Training Effects and Reliability of Peripheral Perception Test. Int J Environ Res Public Health. 2019;16(24). http://dx.doi.org/10.3390/ijerph16245001 http://ncbi.nlm.nih.gov/pubmed/31835309

22. Ryu D, Abernethy B, Mann DL, Poolton JM, Gorman AD. The role of central and peripheral vision in expert decision making. Perception. 2013;42(6):591-607. http://dx.doi.org/10.1068/p7487 http://ncbi.nlm.nih.gov/pubmed/24422243

23.Paul M, Biswas SK, Sandhu JS. Role of sports vision and eye hand coordination training in performance of table tennis players. Brazilian J Biomotric. 2011;5(2):106-116.

24.Przednowek K, Sliz M, Lenik J, Dziadek B, Cieszkowski S, Lenik P, et al. Psychomotor Abilities of Professional Handball Players. Int $J$ Environ Res Public Health. 2019;16(11). http://dx.doi.org/10.3390/ijerph16111909 http://ncbi.nlm.nih.gov/pubmed/31151149

25.Piras A, Lobietti R, Squatrito S. A study of saccadic eye movement dynamics in volleyball: comparison between athletes and non-athletes. $J$ Sports Med Phys Fitness. 2010;50(1):99-108. http://ncbi.nlm.nih.gov/pubmed/20308980 